\title{
Analysis of Heat Transfer Mechanism for Shelf Vacuum Freeze-Drying Equipment
}

\author{
Hong-Ping Cheng, Shian-Min Tsai, and Chin-Chi Cheng \\ Department of Energy and Refrigerating Air-Conditioning Engineering, National Taipei University of Technology, \\ Taipei City 10608, Taiwan \\ Correspondence should be addressed to Shian-Min Tsai; simon884031@yahoo.com.tw
}

Received 10 September 2013; Revised 8 February 2014; Accepted 25 February 2014; Published 14 May 2014

Academic Editor: Ching-Song Jwo

Copyright (C) 2014 Hong-Ping Cheng et al. This is an open access article distributed under the Creative Commons Attribution License, which permits unrestricted use, distribution, and reproduction in any medium, provided the original work is properly cited.

\begin{abstract}
Vacuum freeze-drying technology is applicable to the process of high heat-sensitive products. Due to the long drying period and extremely low processing temperature and pressure, the uniform and efficiency of heat transfer fluid temperature in shelf are critical for product quality. Therefore, in this study, the commercial computer fluid dynamics (CFD) software, FLUENT, was utilized for three-dimension numerical simulation of the shelf vacuum freeze-drying process. The influences of different inlet and outlet positions for shelves on the uniformity of the flow rate and temperature were discussed. Moreover, it explored the impacts on the temperature gradient of shelves after heat exchange of different flow rates and low temperature materials. In order to reduce the developing time and optimize the design, the various secondary refrigerants in different plies of shelves were investigated. According to the effect of heat exchange between different flow rates and low temperature layer material shelves on the temperature gradient of shelves surface, the minimum temperature gradient was $20 \mathrm{~L} / \mathrm{min}$, and the maximum was $2.5 \mathrm{~L} / \mathrm{min}$.
\end{abstract}

\section{Introduction}

Vacuum freeze-drying technology is widely used for manufacturing pharmaceuticals. The requirements of this technology are process optimization and long-term storage stability. There are three stages in the complete vacuum freeze-drying process, such as freezing, primary drying, and secondary drying. Most of the water is frozen to the ice during the freezing stage, and then the ice is removed by sublimation during the primary drying stage. During the secondary drying stage, the temperature is usually elevated to remove the residual water of the products $[1,2]$. Due to the extremely rigor conditions of vacuum freeze-drying process, such as low temperature, high vacuum, and long processing period, the process stability and efficiency would be crucial for product quality.

In the vacuum freeze-drying process, before all the ice is removed from the product, increasing the shelf temperature into the secondary drying would likely cause collapse or eutectic melt of the products. Therefore, the controllability of the temperature of the heat-transfer fluid in the shelf is very important for product quality during the freezedrying process. Many studies would like to find out how the temperature of the heat-transfer fluid in the shelf affected the freeze-drying process. Liapis and Bruttini [3] constructed the operational control policies by the presented exergy expressions to minimize the irreversibilities occurring in a freeze-drying system and enhance the efficiency of energy utilization in lyophilization. Patel et al. [4] measured the temperature of $5 \%$ mannitol and $5 \%$ sucrose by thermocouple to determine the setting shelf temperature and understood the time of primary drying end by product temperature. Gieseler et al. [5] investigated the better drying parameters by measuring the total amount of removed water from the product of pure water and a $5 \%(\mathrm{w} / \mathrm{w})$ mannitol at different pressure and shelf temperature settings, performed in both laboratory and pilot scale freeze dryers. For the pharmaceutical and protein formulations, the collapse temperature and the thermal transition were utilized to find out the optimal heat-transfer fluid temperature of shelf and chamber pressure settings required to achieve the target product temperature $[6,7]$. For food products, Sablani and Rahman [8] indicated 
that the heat-transfer temperature of shelf maintained in $-45 \sim 15^{\circ} \mathrm{C}$ during primary drying process would result in the best quality of drying abalone, potato, and brown dates.

From the above literatures, one can see that the heattransfer fluid temperature of shelf is one of the most important factors in drying process. Therefore, some technologies, such as manometric temperature measurement (MTM), had been used to determine the optimal shelf temperature, and the expert system was utilized to estimate the required shelf temperature for maintaining product temperature $[9,10]$. In addition, some studies employed the finite element analysis for $2 \mathrm{D}$ simulation of sublimation and heat transfer [11, 12], discussing the contact heat transfer between shelf and glass bottle $[13,14]$ and investigating the temperature distribution between glass bottle and product during the drying cycle $[15,16]$. However, the rare literature discussed the flow pattern of fluid inside shelves, design of shelves, and effect of fluid flow and temperature.

The objective of this paper is to investigate the heat transfer rate of the fluid in shelf by using CFD method. Several factors, such as the location of inlet and outlet of the fluid in shelf and mass flow rate, are also discussed in order to improve the efficiency of shelf for the laboratory scale vacuum freeze-drying system.

\section{Operating Conditions}

In this paper, a commercial CFD software, FLUENT, was adopted to simulate all heat transferring processes in the heat exchanger, in order to optimize the design. Shelf is one of the most important devices in the vacuum freezedrying system, because of its capability to heat and cool the products. Therefore, several designs and their operating procedures will be investigated in the study. The efficient shelf is able to reduce the required energy of vacuum freeze-drying equipment during drying process and uplifting the quality of dried product. The $50 \%$ ethylene glycol solution flowing into the shelf served as the secondary refrigerant. Figure 1 shows the schematic drawing of the freeze-drying system, including (a) vacuum chamber, (b) shelf, (c) cold trap, (d) vacuum pump, (e) heat exchanger, (f) condensers, (g) expansion valve, and (h) compressors.

This study would focus on numerical simulation of the flow field and heat-transfer fluid properties conducted for internal flow channel of shelves, including different inlet positions and inlet velocities. The simulation included five cases, as shown in Figure 2 for the detail schematic drawings. Case 1 is the geometric shape of the shelves of vacuum freezedrying machine. The inlet position is at the top, and the outlet position is at the bottom, as shown in Figure 2(a). For Case 2 , the inlet position is at the bottom, and the outlet position is at the top, as shown in Figure 2(b). For Case 3, both the inlet and outlet are at the bottom, as shown in Figure 2(c). For Case 4, both the inlet and outlet are at the top, as shown in Figure 2(d). For Case 5, the increased part is at the bottom, and inlet and outlet are both at the bottom, as shown in Figure 2(e).

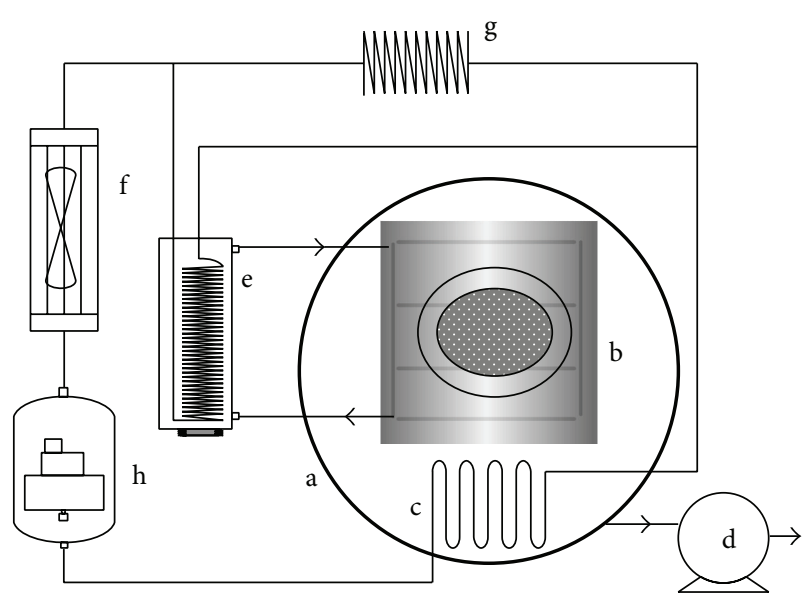

FIGURE 1: Schematic drawing of the freeze-drying system.

2.1. Boundary Conditions. A CFD software, FLUENT, was adopted to simulate the heat exchanging process. Several assumptions during the simulation were made as follows: (1) steady-state flow field; (2) the viscous model uses Laminar; (3) the pressure-velocity coupling uses Simple; (4) the convection-diffusion term uses First Order Upwind; (5) the material is maintained at a constant temperature of $233 \mathrm{~K}$ in the computational process.

The numbers of grids in Case 1 to Case 4 were 1304471 and that in Case 5 were 1308602 . The computing range under hypothetical simulation conditions covered one inlet, one outlet, and liquid entering into shelves, while others were solid boundaries. The pipes through the shelves were set as square pipes after hydraulic diameter calculation, so that grids in GAMBIT were used as a hex map. The grids were $1 \mathrm{~mm}$ per unit in $X$-direction after grid testing, $2 \mathrm{~mm}$ per unit in $Y$-direction, and $2 \mathrm{~mm}$ per unit in $Z$-direction, as shown in Figure 3. The three-dimensional graphics of shelves and shelf flow channel as shown in Figure 3(a) and the grids exterior were shown in Figure 3(b) to Figure 3(d).

The boundary conditions of Cases 1 to 5 are as follows. (1) Inlet and outlet boundaries: the boundary condition of inlet is set as velocity inlet; the inlet velocities are $2.5 \mathrm{~L} / \mathrm{min}, 5 \mathrm{~L} / \mathrm{min}$, $10 \mathrm{~L} / \mathrm{min}$, and $20 \mathrm{~L} / \mathrm{min}$, respectively; the inlet temperature was fixed at $253 \mathrm{~K}$; the outlet boundary was set as outflow; (2) heat transfer fluid entering shelves: the fluid boundary condition settings adopt a 50\% ethylene glycol solution; the fluid properties had density of $1085 \mathrm{~kg} / \mathrm{m}^{3}$, specific heat of $3490 \mathrm{~J} / \mathrm{kg}-\mathrm{K}$, heat transfer coefficient of $0.42 \mathrm{w} / \mathrm{m}-\mathrm{k}$, and viscosity coefficient of $0.029 \mathrm{~kg} / \mathrm{m}-\mathrm{s}$; (3) solid boundary: this solid boundary was set as a wall; the material was steel, and the wall surface was set as heat flux; it was assumed that the top contacts low temperature material was at a preset temperature of $233 \mathrm{~K}$.

2.2. Method of Analysis. For simulating the freeze-drying process of heat transfer fluid in shelf, determination of flow patterns is the first step. Reynolds number is usually adopted 


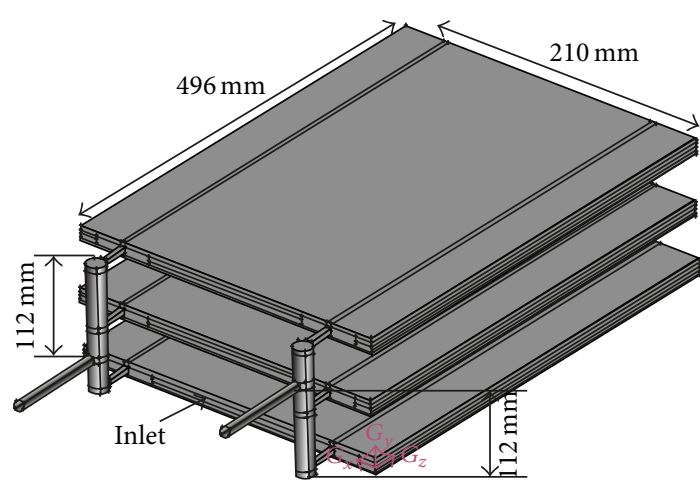

(a)

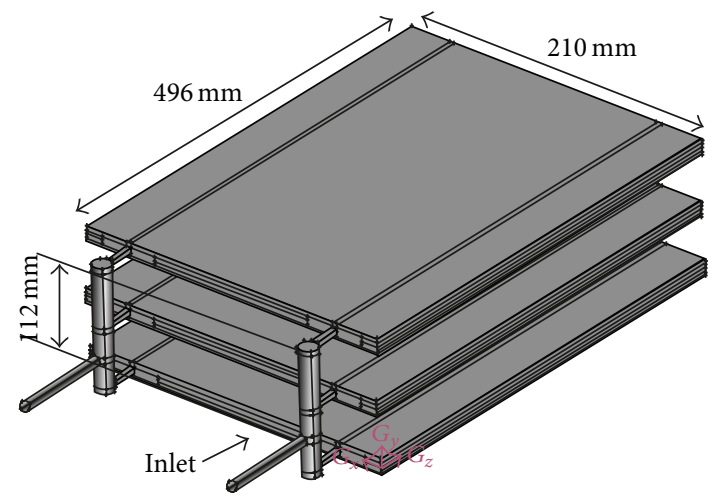

(c)

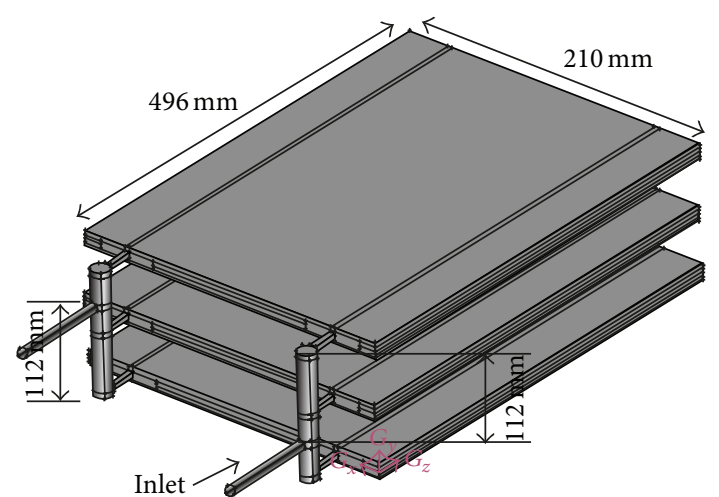

(b)

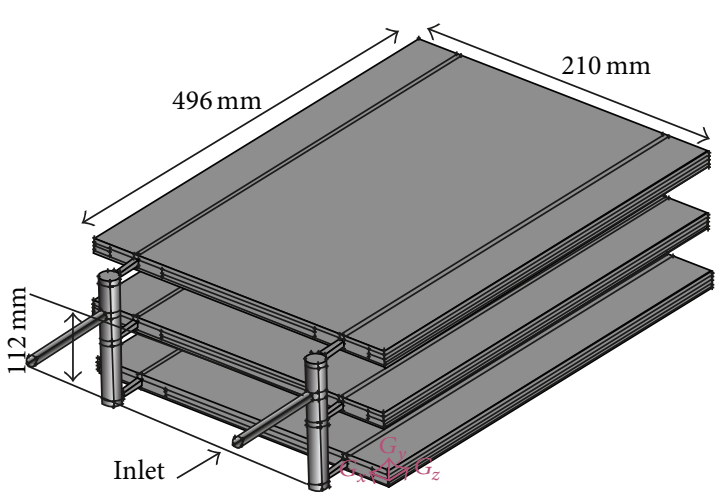

(d)

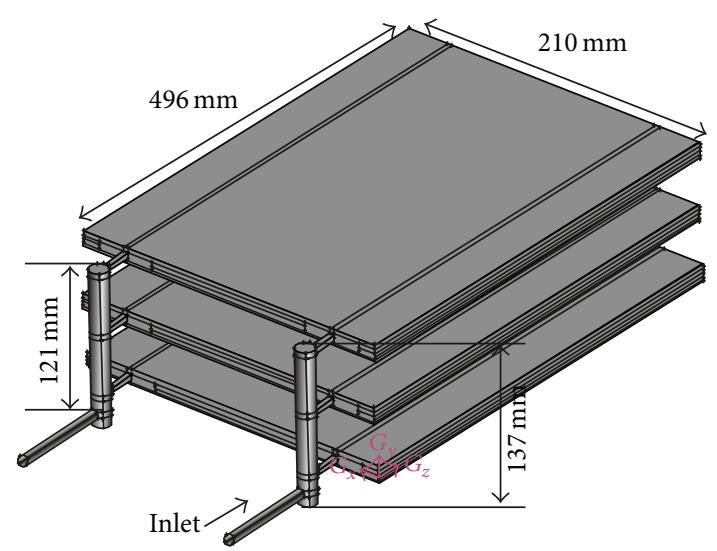

(e)

Figure 2: Geometric shapes of (a) Case 1, (b) Case 2, (c) Case 3, (d) Case 4, and (e) Case 5.

to predict the flow patterns in different flow situations. It can be calculated as

$$
\operatorname{Re}=\frac{\rho V d_{i}}{\mu},
$$

where $\rho$ is the density $\left(\mathrm{kg} / \mathrm{m}^{3}\right), V$ is the average velocity $(\mathrm{m} / \mathrm{s}), d_{i}$ is the hydraulic diameter $(\mathrm{m})$, and $\mu$ is the viscosity $(\mathrm{kg} / \mathrm{m}-\mathrm{s})$.
In this study, the heat transfer fluid in the shelf utilized ethylene glycol solution, with a concentration ratio of $50 \%$. Its thermodynamic properties are $\rho=1089 \mathrm{~kg} / \mathrm{m}^{3}$, $d_{i}=7.92 \mathrm{~mm}$, and $\mu=0.0265 \mathrm{~kg} / \mathrm{m}$-s. These thermodynamic properties varied with environmental temperature, according to the source of the thermodynamic properties of NIST (National Institute of Standards and Technology). The Reynolds number of the heat transfer fluid in the shelf can be calculated according to (1). The calculated Reynolds number 


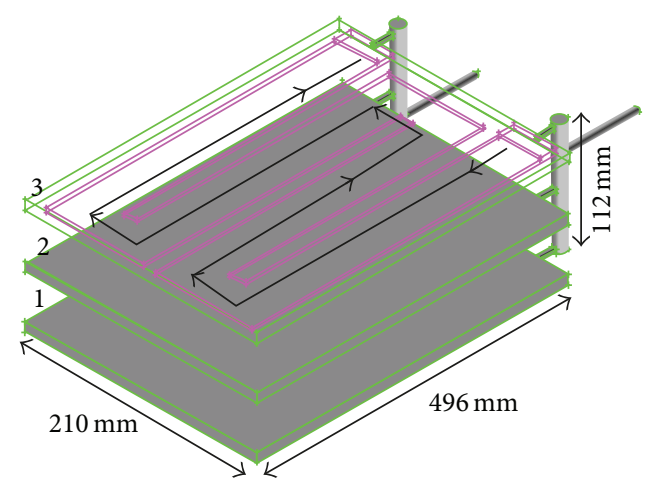

(a)

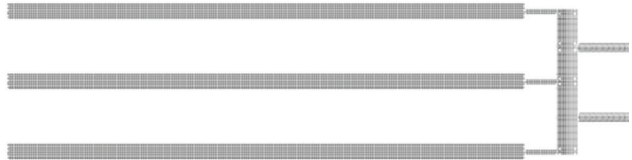

(c)

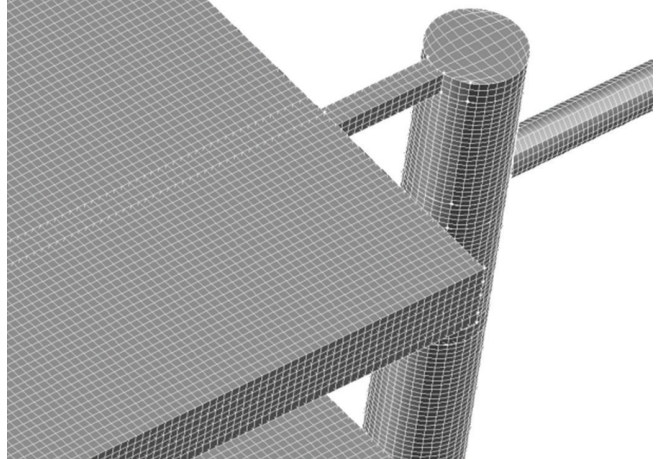

(b)

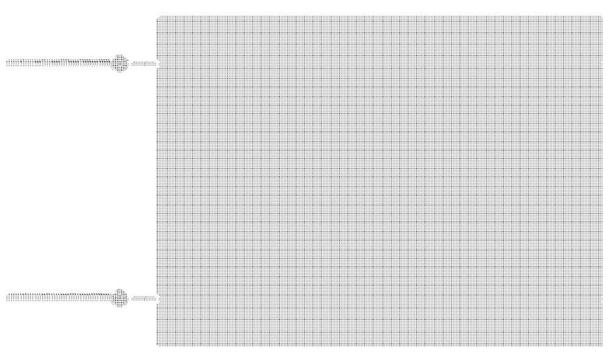

(d)

FIGURE 3: Three-dimensional graphics of shelves and shelf flow channel: (a) overall dimensions of shelves and flow channel structure; (b) local grid structure distribution; (c) side view of overall grid structure distribution; (d) top view of overall grid structure distribution.

was 12 , which is less than 2300. According to the calculated Reynolds number, the inlet flow is decided as the laminar. Thus, the CFD simulation for all the cases was according to the laminar model.

2.3. Heat Transfer Rate. This study would focus on the heattransfer fluid in shelf and heat exchange with freeze products. Therefore, the heat transfer rate was calculated as

$$
Q_{c}=\overline{h_{c}} A_{s}\left(T_{s}-T_{A}\right) \text {, }
$$

where $Q_{c}$ is the heat transfer rate, $\bar{h}_{c}$ is convective heat transfer coefficient, $A_{s}$ is the body surface area, $T_{s}$ is the body wall surface temperature, and $T_{A}$ is the ambient temperature.

For calculating $Q_{c}$, the Nusselt number was calculated first. It can be calculated as

$$
\operatorname{Pr}=\frac{C_{p} \mu}{k}
$$

where $\operatorname{Pr}$ is the Prandtl number, $C_{p}$ is the specific heat $(\mathrm{j} / \mathrm{kg}-\mathrm{k}), \mu$ is the viscosity $(\mathrm{kg} / \mathrm{m}-\mathrm{s})$, and $k$ is the thermal conductivity $(\mathrm{w} / \mathrm{m}-\mathrm{k})$. The Prandtl number was located in the range of $0.48<\operatorname{Pr}<16700$.

The laminar Nusselt number equation is used for calculating $\overline{h_{c}}$ as follows:

$$
\mathrm{Nu}=\frac{\overline{h_{c}} D}{k}=1.86\left(\frac{V D \rho}{\mu}\right)^{1 / 3}\left(\frac{C_{p} \mu}{k}\right)^{1 / 3}\left(\frac{D}{L}\right)^{1 / 3}\left(\frac{\mu}{\mu_{w}}\right),
$$

where $\mathrm{Nu}$ is the Nusselt number, $\overline{h_{c}}$ is the convective heat transfer coefficient $\left(\mathrm{W} / \mathrm{m}^{2}-\mathrm{K}\right), D$ is the hydraulic diameter (m), $k$ is the thermal conductivity $(\mathrm{w} / \mathrm{m}-\mathrm{k}), V$ is the velocity $(\mathrm{m} / \mathrm{s}), \mu$ is the viscosity $(\mathrm{kg} / \mathrm{m}-\mathrm{s}), \mu_{w}$ is the wall viscosity (kg/m-s), $\rho$ is the density $\left(\mathrm{kg} / \mathrm{m}^{3}\right), C_{p}$ is the specific heat $(\mathrm{j} / \mathrm{kg}-\mathrm{k})$, and $L$ is the characteristic length $(\mathrm{m})$.

\section{Results and Discussion}

For the laboratory scale vacuum freeze-drying system, most of the process is carried out on the shelves. How to provide heat equally and efficiently on the shelves during the freezedrying process would be crucial for product quality. Therefore, in five different types design of shelves, two problems are discussed: (1) the effect of different inlet and outlet positions on the same flow rate and temperature when the fluid flows into different plies of shelves; (2) the effects of different flow rates on the same temperature gradients of shelves after heat exchange between fluid in shelves and low temperature material.

In the application of a laboratory scale vacuum freezedrying machine, only the first and second plies of shelves are used, the third ply is mostly idle. Therefore, only the temperature, velocity, and heat transfer rate distribution of the first and second plies are considered in this study. The results of the third ply are used as a reference.

The simulated results were shown in Figure 4. In Figure 4 , the flow rate of the shelves was $2.5 \mathrm{~L} / \mathrm{min}$, In Case 1 , 

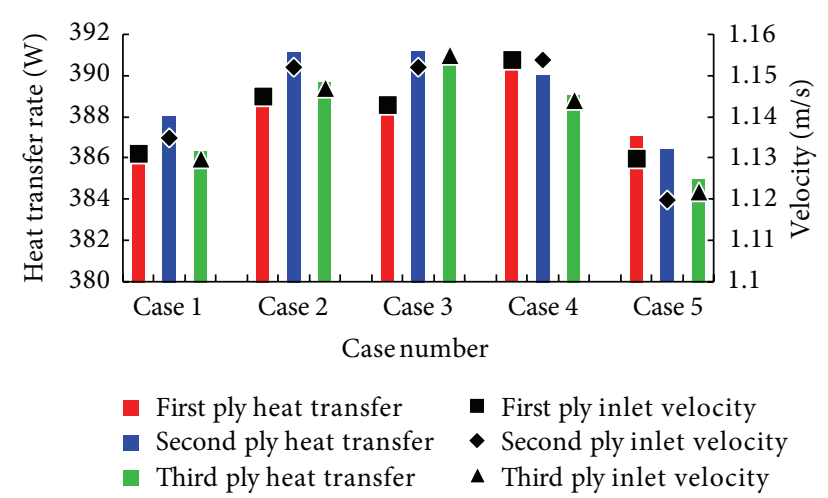

FIGURE 4: Variation of heat transfer rate with respect to inlet velocity at $2.5 \mathrm{~L} / \mathrm{min}$ in various cases.

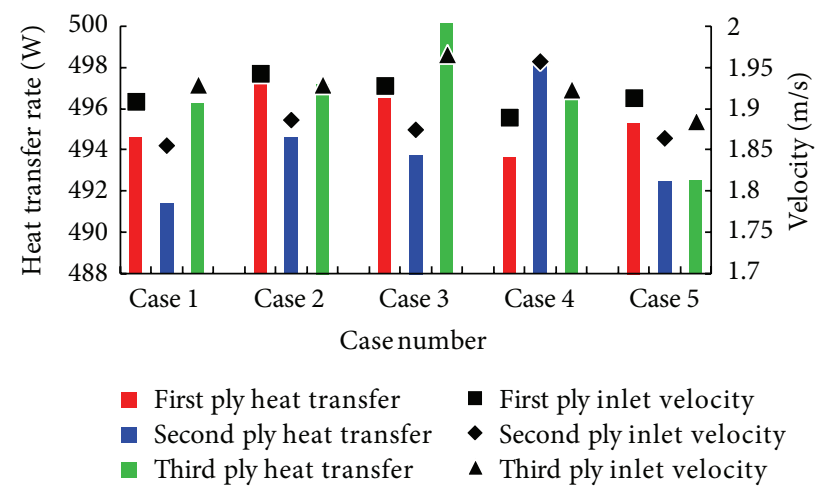

FIGURE 5: Variation of heat transfer rate with respect to inlet velocity at $5 \mathrm{~L} / \mathrm{min}$ in various cases.

the difference of inlet velocity between the first ply and the third ply of the shelf is small. The performances of $Q_{c}$ for the first and second plies were $386.689 \mathrm{~W}$ and $388.015 \mathrm{~W}$, respectively. The difference between the first and second plies was $1.326 \mathrm{~W}$. At the flow rate of $2.5 \mathrm{~L} / \mathrm{min}$ in Case 4 , the first and the second plies have the same inlet velocity of $1.154 \mathrm{~m} / \mathrm{s}$, and the inlet velocity of third ply was $1.144 \mathrm{~m} / \mathrm{s}$. The distribution of heat transfer rate $Q_{c}$ for the first, second, and third plies was $390.728 \mathrm{~W}, 390.035 \mathrm{~W}$, and $389.098 \mathrm{~W}$, respectively. The difference of heat transfer rate $Q_{c}$ between the first and second plies was $0.693 \mathrm{~W}$, and the difference of the third ply is $1.63 \mathrm{~W}$. The heat transfer rate of the three shelves in Case 4 was more uniform than other cases. Therefore, when the flow rate was $2.5 \mathrm{~L} / \mathrm{min}$, it was suggested to use the geometrical model of Case 4 as the reference design.

In Figure 5, the inlet flow rate was set as $5 \mathrm{~L} / \mathrm{min}$. The inlet velocities of the first, second, and third plies of shelf in Case 1 were $1.909 \mathrm{~m} / \mathrm{s}, 1.855 \mathrm{~m} / \mathrm{s}$, and $1.929 \mathrm{~m} / \mathrm{s}$, respectively. In terms of performance in heat transfer rate $Q_{c}$, the heat transfer rate of the first, second, and third plies was $494.631 \mathrm{~W}$, $491.430 \mathrm{~W}$, and $496.265 \mathrm{~W}$, respectively. The difference of heat transfer rates between the first and second plies was $4.551 \mathrm{~W}$. In Case 3, the heat transfer rates $Q_{c}$ of the first, second, and third plies were $496.524 \mathrm{~W}, 493.756 \mathrm{~W}$, and $500.159 \mathrm{~W}$, respectively. The difference between the first and second plies

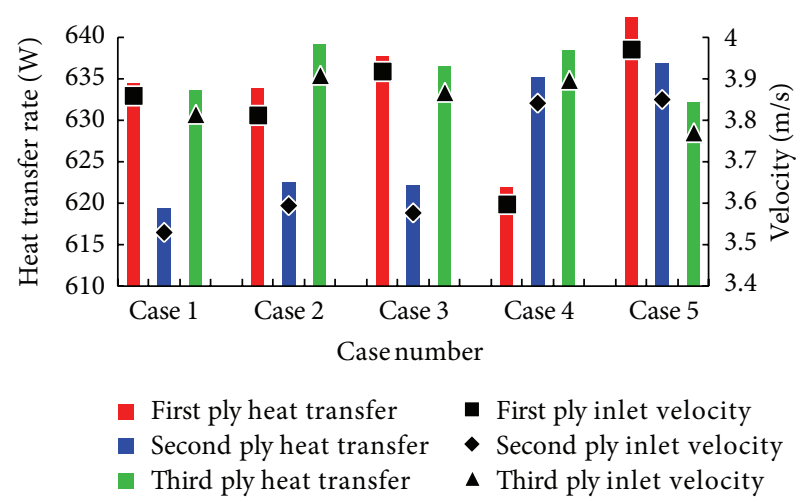

FIGURE 6: Variation of heat transfer rate with respect to inlet velocity at $10 \mathrm{~L} / \mathrm{min}$ in various cases.

was $2.768 \mathrm{~W}$, which was the smallest difference. In addition, the difference of heat transfer rate $Q_{c}$ between the first and second plies of shelves in Case 5 was $2.839 \mathrm{~W}$. Therefore, when the inlet flow rate was $5 \mathrm{~L} / \mathrm{min}$, Case 1 could be replaced by the geometric shape of Case 3 .

In Figure 6, the inlet flow rate was set as $10 \mathrm{~L} / \mathrm{min}$. The simulating results of Case 1 show that the inlet velocity of the first, second, and third plies was $3.859 \mathrm{~m} / \mathrm{s}, 3.531 \mathrm{~m} / \mathrm{s}$, and $3.816 \mathrm{~m} / \mathrm{s}$, respectively. The inlet velocity of the second ply was lower than that of the other two plies. In terms of distribution of heat transfer rate $Q_{c}$, the first, second, and third plies were $634.513 \mathrm{~W}, 619.403$, and $633.628 \mathrm{~W}$, respectively. The difference of $Q_{c}$ between the first ply and the second ply was $14.228 \mathrm{~W}$. In the other cases, the differences of $Q_{c}$ between the first and second plies in Cases 2, 3, and 4 were $11.392 \mathrm{~W}$, $15.535 \mathrm{~W}$, and $13.258 \mathrm{~W}$, respectively. The differences in these cases were above $10 \mathrm{~W}$. However in Case 5, the difference of $Q_{c}$ between the first and second plies was only $5.553 \mathrm{~W}$, which was the smallest among all the cases. Therefore, when the flow rate was $10 \mathrm{~L} / \mathrm{min}$, the geometric shape of Case 5 could be used for the design.

In Figure 7, the inlet flow rate was set as $20 \mathrm{~L} / \mathrm{min}$. The shelf inlet velocities of the first and second plies were similar in Case 5. The inlet velocities of the first and second plies were $7.767 \mathrm{~m} / \mathrm{s}$ and $7.678 \mathrm{~m} / \mathrm{s}$, respectively. Their difference was only $0.089 \mathrm{~m} / \mathrm{s}$, and the difference in other cases was above $0.357 \mathrm{~m} / \mathrm{s}$. For heat transfer rate $Q_{c}$, the difference was only $4.631 \mathrm{~W}$ in Case 5, and the difference in the other cases was $16.641 \mathrm{~W} \sim 13.435 \mathrm{~W}$. Therefore, when the flow rate was $20 \mathrm{~L} / \mathrm{min}$, the geometric shape of Case 5 was suggested.

The simulating results have a closer relationship between temperature gradient and heat flow rate in all the cases. Average results of all the cases were shown in Figure 8. In the flow rate range from $2.5 \mathrm{~L} / \mathrm{min}$ to $20 \mathrm{~L} / \mathrm{min}$, the temperature gradient decreased from 0.062 to $0.018 \mathrm{~K} / \mathrm{cm}$ monotonically, and the heat transfer rate increased from 388.7 to $775.5 \mathrm{~W}$ monotonically. The flow rate had an inverse linear relationship with the temperature gradient, however, a positive linear relationship with the heat transfer rate. 


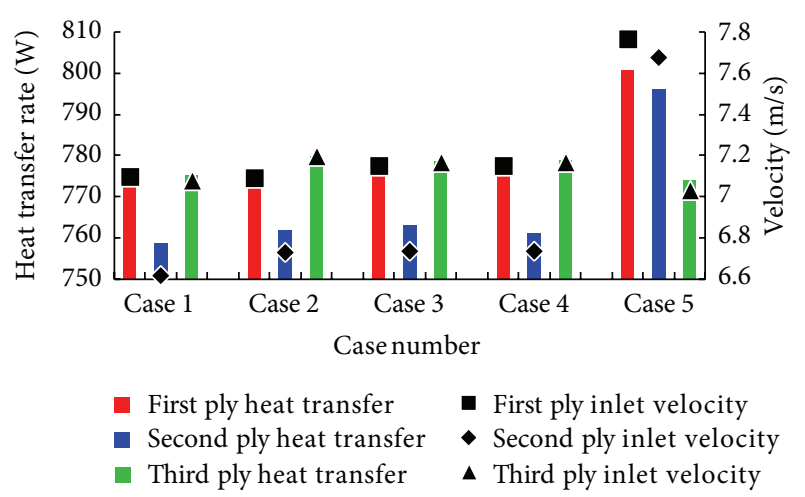

FigURE 7: Variation of heat transfer rate with respect to inlet velocity at $20 \mathrm{~L} / \mathrm{min}$ in various cases.

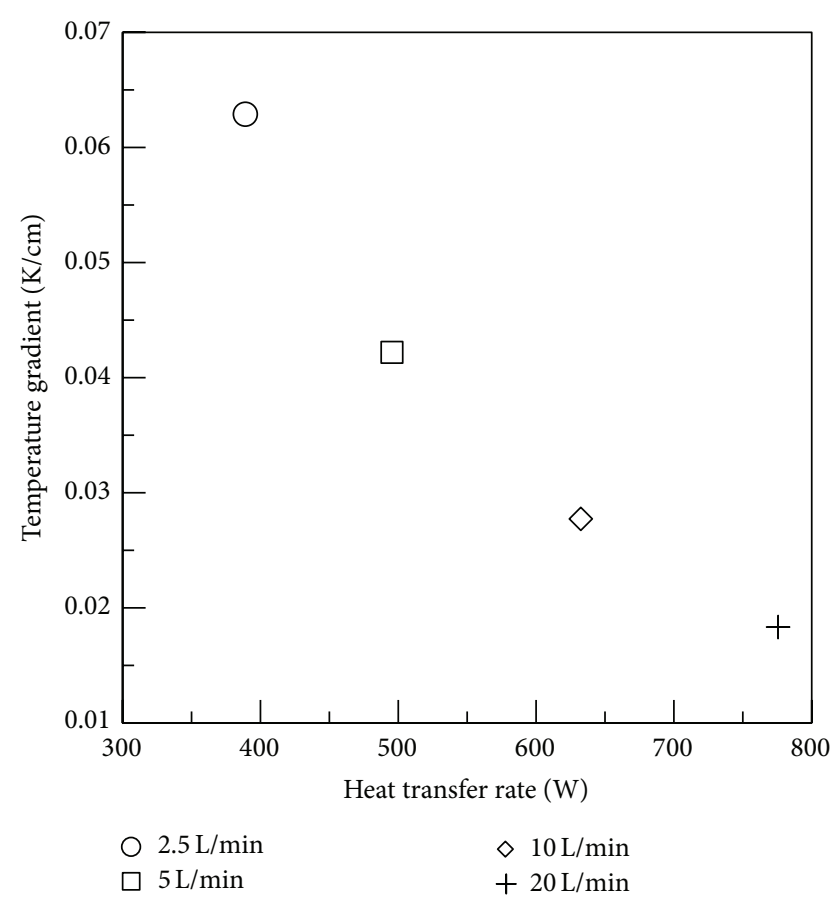

FIGURE 8: Temperature gradient with respect to heat transfer rate in various inlet velocities.

\section{Conclusions}

Vacuum freeze-drying is a long-term process and has a close relation to temperature. This study discussed the effect of different inlet and outlet positions under the same flow rate and temperature of different plies of shelves and investigated the influences of different flow rates under the same temperature gradient of shelves after heat exchange between fluid and low temperature material in the shelves. The conclusions are as follows.

(1) When the flow rate was $2.5 \mathrm{~L} / \mathrm{min}$, the inlet velocities of different plies of shelves are closest in Case 4. The difference of heat transfer rate $Q_{c}$ between the first and second plies was only $0.693 \mathrm{~W}$. This was the preferred design for the cases of lower flow rates, and it may result in similar quality of materials even with different plies.

(2) Although Case 1 was an actual case, when the flow rate was $5 \mathrm{~L} / \mathrm{min}$, the results show that Case 3 was more appropriate, and the difference between the first and second plies was $2.768 \mathrm{~W}$.

(3) Case 5 has a better heat transfer rate when the flow rates were $10 \mathrm{~L} / \mathrm{min}$ and $20 \mathrm{~L} / \mathrm{min}$. The users can adopt the geometric shape of Case 5 when requiring the higher flow rates. In addition, the heat transfer rate in Case 5 was similar to that of Case 3 , when the flow rate was $5 \mathrm{~L} / \mathrm{min}$. Therefore, the geometric shape of Case 5 allows a wide range of flow rates.

(4) The temperature gradient and heat transfer rate had a close relationship with the flow rate. The flow rate had an inverse linear relationship with the temperature gradient, however, a positive linear relationship with the heat transfer rate.

The above results can serve as references for future studies on the geometric production of shelves and setting inlet flow rates for different flow rates.

\section{Conflict of Interests}

The authors declare that there is no conflict of interests regarding the publication of this paper.

\section{Acknowledgment}

This study was sponsored by the National Science Council, Taiwan, NSC (100-2221-E-027-074).

\section{References}

[1] A. A. Barresi, R. Pisano, D. Fissore et al., "Monitoring of the primary drying of a lyophilization process in vials," Chemical Engineering and Processing: Process Intensification, vol. 48, no. 1, pp. 408-423, 2009.

[2] M. J. Pikal, "Freeze-drying of proteins-part II: formulation selection," BioPharm, vol. 3, pp. 26-30, 1990.

[3] A. I. Liapis and R. Bruttini, "Exergy analysis of freeze drying of pharmaceuticals in vials on trays," International Journal of Heat and Mass Transfer, vol. 51, no. 15-16, pp. 3854-3868, 2008.

[4] S. M. Patel, T. Doen, and M. J. Pikal, "Determination of end point of primary drying in freeze-drying process control," AAPS PharmSciTech, vol. 11, no. 1, pp. 73-84, 2010.

[5] H. Gieseler, W. J. Kessler, M. Finson et al., "Evaluation of tunable diode laser absorption spectroscopy for in-process water vapor mass flux measurements during freeze drying," Journal of Pharmaceutical Sciences, vol. 96, no. 7, pp. 1776-1793, 2007.

[6] X. Tang and M. J. Pikal, "Design of freeze-drying processes for pharmaceuticals: practical advice," Pharmaceutical Research, vol. 21, no. 2, pp. 191-200, 2004.

[7] R. Pisano, D. Fissore, and A. A. Barresi, "Freeze-drying cycle optimization using model predictive control techniques," Industrial and Engineering Chemistry Research, vol. 50, no. 12, pp. 7363-7379, 2011. 
[8] S. S. Sablani and M. S. Rahman, "Pore formation in selected foods as a function of shelf temperature during freeze drying," Drying Technology, vol. 20, no. 7, pp. 1379-1391, 2002.

[9] X. Tang, S. L. Nail, and M. J. Pikal, "Freeze-drying process design by manometric temperature measurement: design of a smart freeze-dryer," Pharmaceutical Research, vol. 22, no. 4, pp. 685-700, 2005.

[10] H. Gieseler, T. Kramer, and M. J. Pikal, "Use of manometric temperature measurement (MTM) and SMARTŮ freeze dryer technology for development of an optimized freeze-drying cycle," Journal of Pharmaceutical Sciences, vol. 96, no. 12, pp. 3402-3418, 2007.

[11] W. J. Mascarenhas, H. U. Akay, and M. J. Pikal, "A computational model for finite element analysis of the freeze-drying process," Computer Methods in Applied Mechanics and Engineering, vol. 148, no. 1-2, pp. 105-124, 1997.

[12] A. Hottot, R. Peczalski, S. Vessot, and J. Andrieu, "Freeze-drying of pharmaceutical proteins in vials: modeling of freezing and sublimation steps," Drying Technology, vol. 24, no. 5, pp. 561$570,2006$.

[13] Y.-Y. Kim and K.-S. Lee, "Comparative numerical study of freeze drying of solution and spray-frozen particles in trays and vials," Numerical Heat Transfer A: Applications, vol. 54, no. 4, pp. 406425, 2008.

[14] M. Brülls and A. Rasmuson, "Heat transfer in vial lyophilization," International Journal of Pharmaceutics, vol. 246, no. 1-2, pp. 1-16, 2002.

[15] S. H. Bae, J. H. Nam, C. S. Song, and C.-J. Kim, "A numerical model for freeze drying processes with infrared radiation heating," Numerical Heat Transfer A: Applications, vol. 58, no. 5, pp. 333-355, 2010.

[16] M. P. Schoen, B. K. Braxton, L. A. Gatlin, and R. P. Jefferis III, "A simulation model for the primary drying phase of the freezedrying cycle," International Journal of Pharmaceutics, vol. 114, no. 2, pp. 159-170, 1995. 

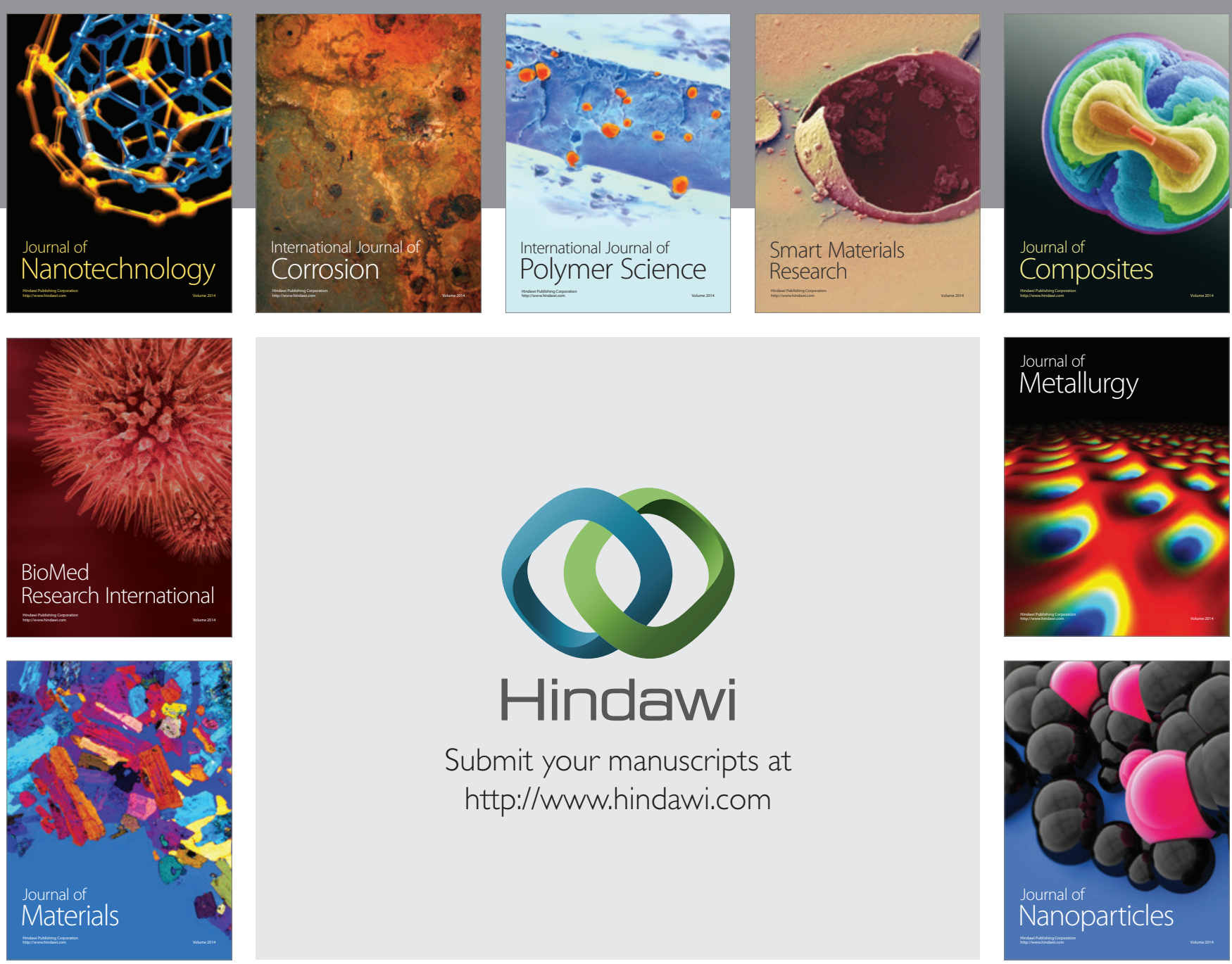

Submit your manuscripts at http://www.hindawi.com
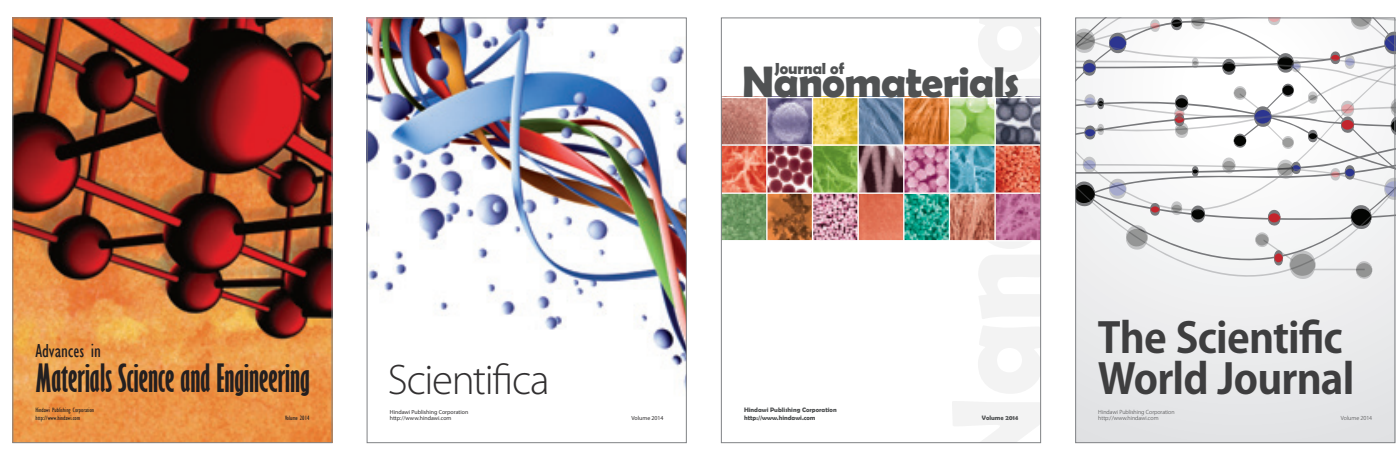

\section{The Scientific World Journal}
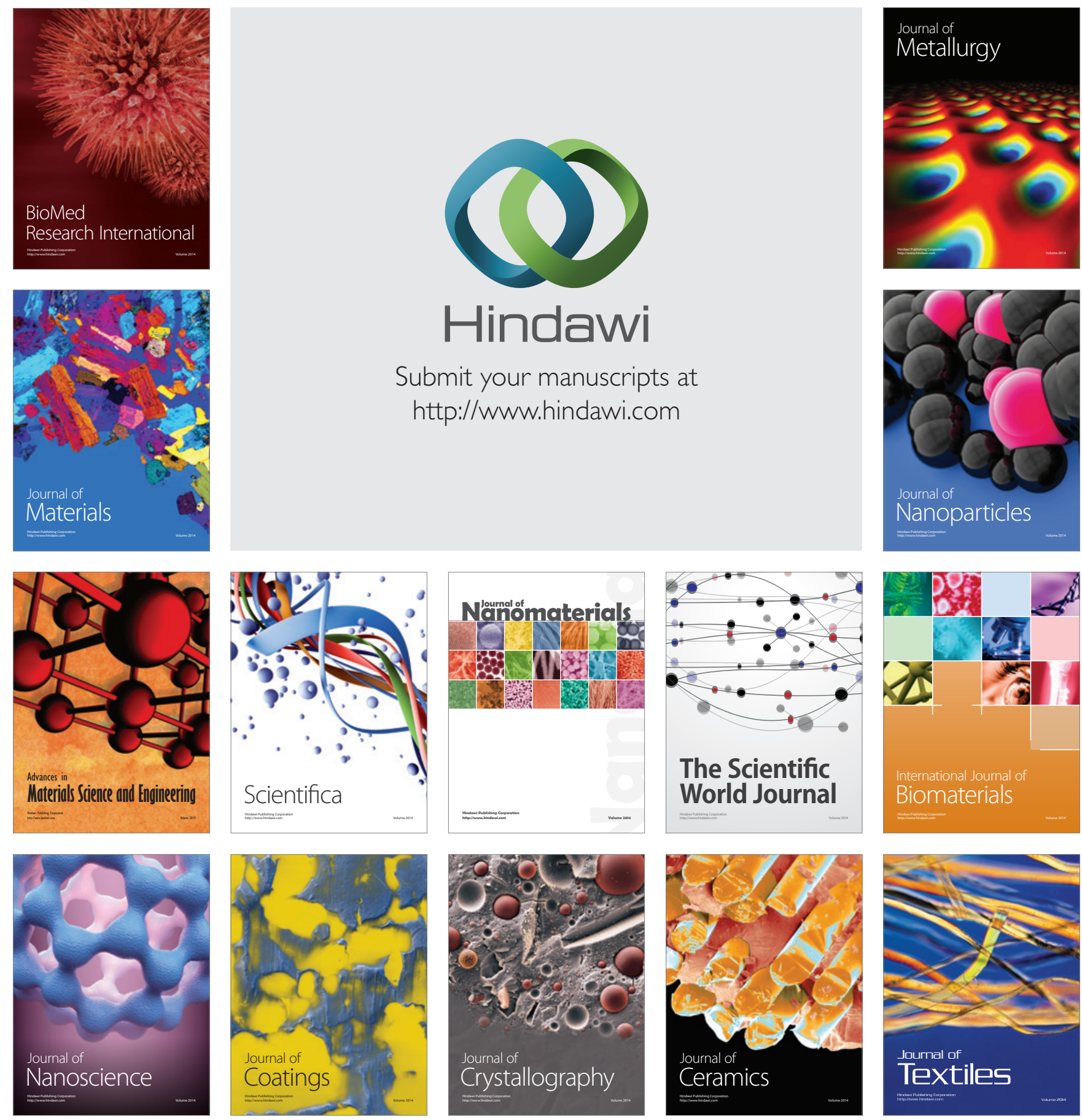